\title{
perifèria
}

Número 11, desembre 2009

www. periferia.name

\section{Esdevenir antropòleg}

\section{Lluís Mallart Guimerà - Centre National de la Recherche Scientifique i de la} Universitat de Paris $\mathrm{X}^{1}$.

\section{Resum}

Text de la conferència que havia preparat, de les coses doncs que potser no vaig dir i que volia dir, d'altres que potser no pensava dir i vaig dir si es que ara tinc prou memòria per a recordarles... Sigui el que sigui, us ofereixo aquest text tot desitjantvos que al final de la vostra vida pugueu dir "vaig fer ben fet d'escollir Antropologia... m'ho he passat molt bé...!"

\section{Abstract}

This is the text of the conference I had prepared for the session, with things that possibly I did not say (and I wanted to say), or things that I said and I did not want to say (if I still have enough memory for recording them ...). Anyway, I want to offer to all of you this text with the wish that at the end of your life you can say "I made the right decision studying Anthropology... I got a

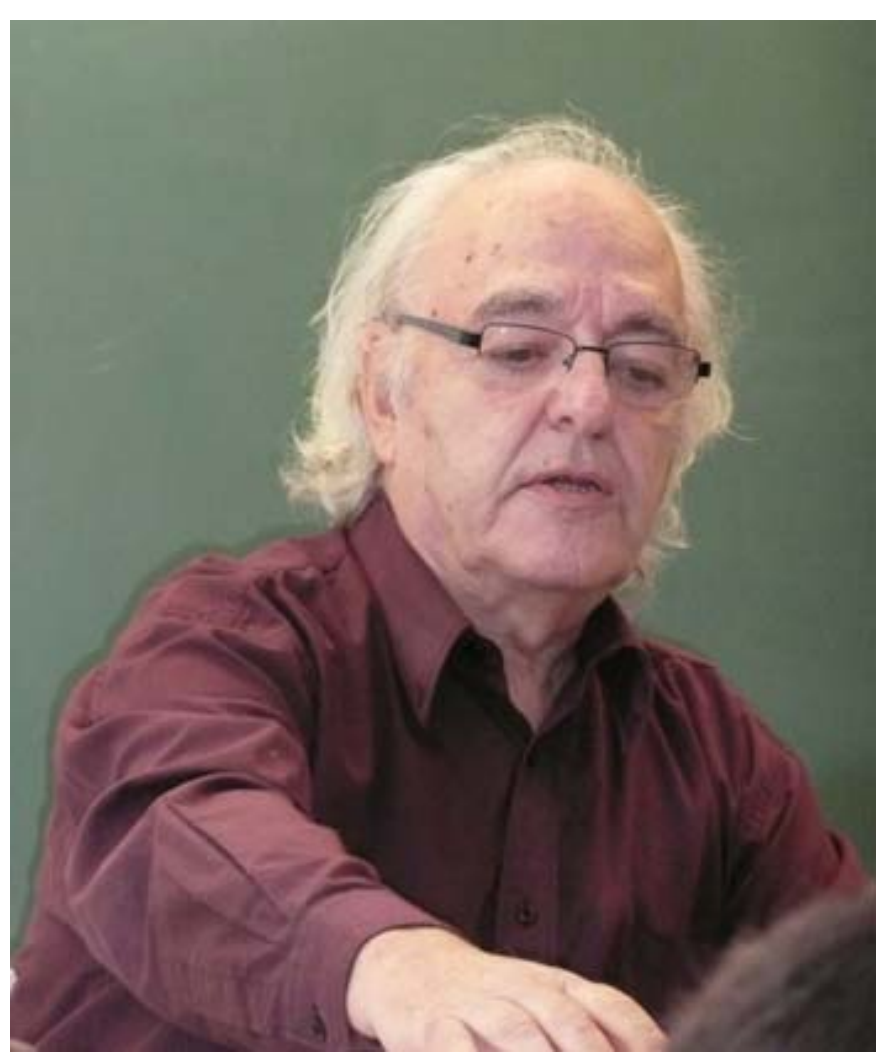
lot of fun...!"

És un goig molt gran trobar-me en aquesta sala tan plena. És tot un símbol. Uns que arriben i un... que se'n va. Uns que volen iniciar-se en aquesta disciplina i jo que ja estic en aquella fase que podríem dir-ne "terminal" no en termes mèdics sinó existencials...

\footnotetext{
${ }^{1}$ Enviar correspondencia a: lluis.mallart@hotmail.com
} 


\section{perifèria}

Número 11, desembre 2009

www.periferia. name

Bon dia a totes i a tots...

Havia pensat dedicar aquesta conferencia explicant el que significa per un estudiant d'antropologia preparar i defensar la seva tesis de doctorat. Potser perquè en aquells moments, quan vaig rebre la invitació d'estar avui entre vostès, ho estava escrivint dins del marc d'un altre projecte ${ }^{2}$. M'hi vaig repensar i vaig creure que potser seria més útil de començar pel començament parlant simplement de tres termes que d'una manera o altra han configurat la disciplina que han escollit : etnografia, etnologia i antropologia.

Tres termes que formen una tríade que jo considero fonamental per a la nostre disciplina.

Miraré de parlar-ne a partir de la meva pròpia subjectivitat, és a dir, intentant explicar de quina manera, jo, personalment, he viscut el que els uns i els altres han posat darrera aquests mots...

Quan vaig començar a interessar-me per la nostra disciplina (anys 1960), en el nostre país, la paraula "antropologia" només era emprada per a parlar d'antropologia biològica, d'antropologia física, antropologia criminal... en les facultats de Ciències, en les recerques per intentar aclarir el concepte de raça... En aquell temps, a casa nostra, es parlava poc o gens d'antropologia social i/o cultural com es va fer en el món acadèmic a partir del moment en què Esteva Fabregat va crear el departament d'antropologia de la UB a finals de la dècada dels 60.

En els anys 60 en la universitat central de Barcelona s'impartia una assignatura d'una matèria que s'intitulava més o menys L'etnologia dels pobles primitius que la donava August Panyella, que fou director del Museu etnològic de Barcelona.

Quan l'any 1961 arribo a l'Àfrica i començo a interessar-me de debò per la nostra disciplina i faig les meves lectures dels clàssics en Antropologia que encarregava a França, descobreixo un altre terme: el de etnografia sobre el qual tothom semblava estar d'acord en associar-lo al "treball de camp" ...

\footnotetext{
${ }^{2}$ En una mena de Memòries que escric no per a publicar sinó per a no perdre la poca que em queda...
} 


\section{perifèria}

Número 11, desembre 2009

\section{www.periferia.name}

Ja tenim doncs tres termes : etnografia, etnologia i una antropologia, no física, sinó social o cultural que s'està forjant a casa nostra i que encara tardarà uns anys en cristal-litzar-se des d'un punt acadèmic o universitari.

Després de passar vuit anys al Camerún i sis entre els evuzok on vaig aprendre alguna d'aquestes tres coses, vaig anar a França per fer un recyclage... Era l'any 1968. El món universitari estava molt esvalotat. Per a mi, d'una manera molt saludable.

Allí, la paraula gairebé oficial, era la d'etnologia i tots els seus derivats, etnolingüística, etnobotànica, etnomusicologia, etno-medecina... A França no hi havia, i em sembla que encara no n'hi han "doctorats en antropologia". Els doctorats eren o son d'etnologia. El departament on vaig ensenyar durant 22 anys encara es diu "d'etnologia" i el laboratori de recerca del qual encara formo part s'intitula Laboratori d'etnologia i sociologia comparativa. Es cert que a França també s'empra el mot antropologia. El laboratori fundat per en Levi Strauss al col·legi de França que es una gran institució no universitària però de molt prestigi es deia d'Antropologia social. Em sembla que s'ho podia permetre, si tenim en compte que en aquest país veí, l'etnografia, l'etnologia i l'antropologia, com ell mateix ho explica, s'han considerat no com tres disciplines diferents, sinó com tres fases d'una mateixa disciplina que es podrien caracteritzar dient que l'etnografia es la recollida de dades, primer pas; l'etnologia representa l'esforç per a analitzar-los o interpretar-los, el segon pas; i l'antropologia apareix com la temptativa d'una reflexió més general, més teòrica, a partir de les dades i els models d'interpretació proporcionats per l'etnografia i l'etnologia i les altres ciències.

De totes maneres, aquestes fases, etapes o moments d'una mateixa disciplina eren concebudes o almenys així ho entenc jo com íntimament relacionades les unes amb les altres, no com tres etapes successives sinó com moments diferents que s'intercalen els uns amb els altres. No hi ha un moment per fer només l'etnografia i un altre per fer l'etnologia. No es pot fer una bona etnografia sense unes determinades posicions teòriques que dirigeixin el treball etnogràfic. $\mathrm{Ni}$ una antropologia teòrica sense una bona etnografia o etnologia. I el mateix podríem dir 


\section{perifèria}

Número 11, desembre 2009

www.periferia.name

de l'etnologia.

Un altre element important a França era que mai la paraula "etnologia" era reservada únicament a l'estudi de les altres societats.

És cert que l'etnologia francesa ha sigut - per les raons històriques que siguin, però no únicament - una etnologia oberta a l'estudi de les altres societats. Però de la mateixa manera que teníem una sèrie d'etnòlegs especialitzats en l'estudi de les societats africanes, amerindies, de l'Índia, del Nepal, Japó... n'hi havien d'altres que s'especialitzaven en l'estudi de les societats europees. En el nostre departament de la mateixa manera que es podia optar per l'especialitat Africa, Amèrica, India, Asia del sud-est, Oceania es podia optar per l'especialitat Europa...

Quan l'any 1992 m'incorporo a la universitat de Barcelona, campus de Tarragona... tinc la sensació i ben fonamentada de viure en un marc acadèmic en el que l'antropologia i l'etnologia, tenen un altre sentit o uns altres camps d'aplicació.

- No son concebudes com dues etapes d'aquella tríade

- M'apareixen gairebé com dues coses diferents

- Es parla sobretot d'etnologia quan hom es refereix a l'estudi de les altres societats, de les africanes, amerindies...

- En el pla acadèmic : només es lliuren doctorats en antropologia

- Per altra banda, la recerca antropològica estava orientada principalment i casi exclusivament vers l'estudi de la nostra societat. A Tarragona vaig anarhi com a investigador. No tenia obligació de fer classes. De totes maneres vaig oferir-me de fer-ne alguna. M'assignaren una assignatura que en aquells temps (any 1992) encara es deia : Etnologia dels pobles primitius... Jo que no n'havia conegut a cap, de primitiu...!

- A Tarragona, per exemple, s'estudiava i es feien recerques sobre la família i el parentesc, la família de casa nostra, evidentment; es feia antropologia religiosa, dels moviments religiosos de casa nostra: les sectes, per exemple; es feia antropologia urbana, de les ciutats de casa nostra...; es feia antropologia mèdica, sobre les institucions mèdiques de casa nostra... I 


\section{perifèria}

Número 11, desembre 2009

www.periferia. name

m'està bé però...

Què hi feia jo a Tarragona?

Va ser una pregunta que em vaig tenir que fer moltes vegades.

La prova és que el postgrau d'estudis africans amb una orientació clarament etnològica o antropològica que vaig organitzar només va durar tres anys i no es va continuar.

I el postgrau d'estudis asiàtics que volia iniciar amb la col-laboració del CNRS (Centre National de la Recherche Scientifique)no es va poder portar a terme quan tot estava ja preparat.

El Màster d'Antropologia mèdica que vàrem dissenyar i que es va fer mentre estava a la URV, donàrem una importància especial a les "altres medecines" o sistemes mèdics (Asia, Àfrica...) però quan jo vaig deixar la URV aquestes assignatures sobre les altres societats varen desaparèixer.

Algunes explicacions que es donaven llavors: “aquests ensenyaments (l'estudi de les altres societats, és a dir l'etnologia o les etnologies regionals) trenquen amb l'estil de l'antropologia que es fa a la casa...."

Potser m'atreviria a dir que l'estat de les autonomies i les polítiques destinades a la recerca de les identitats perdudes o maltractades, ajudava a que es trobessin més mitjans per portar a terme recerques sobre nosaltres mateixos que sobre els altres. I això potser és vàlid per a totes les autonomies de l'estat espanyol...

Resumint : Fer etnologia era parlar dels altres ; fer antropologia era parlar de nosaltres mateixos.

En incorporar-me al món acadèmic de casa meva, hauria pogut tenir un problema de identitat. No el vaig tenir. $O$ en tot cas, he sobreviscut. Però què era jo: un etnògraf? Un etnòleg? Un antropòleg?

Molt més tard la cosa es podia complicar quan un dia una periodista em feia una entrevista i a l'endemà publicava un article en no se quin diari en el qual deia : "es veu que en Mallart ha fet molt treball de camp, només cal mirar-li les mans..." 


\section{perifèria}

Número 11, desembre 2009

www.periferia.name

Aquella periodista confonia l'etnografia amb l'agricultura....

En resum, he viscut la impressió d'ésser un etnòleg i no un antropòleg. No em sap gens de greu ser etnòleg; només em sap greu que aquesta dicotomia impliqui d'una certa manera: la nostra societat / la societat dels altres; nosaltres, / ells, els altre; i potser: pràctica de la nostra disciplina / teoria de la nostra disciplina...

A mi no em fa res que "de tot plegat" s'en digui antropologia però que sigui una antropologia de totes les societats

Jo penso per altra banda que l'antropologia no té l'exclusiva dels aspectes teòrics de la nostra disciplina, potser ho penso així perquè considero que els termes d'aquella tríade estan íntimament connectats. Penso per exemple que l'etnografia no tan sols genera interpretacions, models i reflexions d'ordre general sinó que també és induïda en el moment de la seva recerca per aspectes d'ordre teòric.

Es així com també penso que l'etnografia no s'acaba ni es redueix amb el treball de camp sinó que es perllonga desprès en els arxius i les biblioteques. És així que es pot ser un excel-lent antropòleg sense haver fet mai directament un treball de camp. Només dic que l'etnografia en el seu aspecte de "treball de camp" és indispensable per a la nostra disciplina, com a tal. Nosaltres, els etnògrafs, etnòlegs o antropòlegs estudiem les societats o determinats aspectes de les societats d'avui, contemporànies i això exigeix a la nostra disciplina - però no a tots els antropòlegs - el mal anomenat "treball de camp"

Sincerament crec que, per una banda, s'ha mitificat una mica massa el treball de camp; i per altre, s'ha desmitificat tant, com en el "Antropòleg innocent", que més aviat ha fet mal a la nostra disciplina... tot volent fer riure als seus lectors...o tot rient-se de l'antropologia. Però l'humor és I'humor...

Potser tinc de dir que I'UAB dins del panorama antropològic de Catalunya és una excepció i ha mostrat una certa sensibilitat per l'interès vers les altres societats: els arxius Murdock, en son un exemple, les recerques sobre Àfrica, Austràlia, Amèrica del Sud... que han acabat amb doctorats, un altre. Jo mateix, durant molts anys vaig impartir cursos de doctorat sobre Àfrica. No podríem dir el mateix de les altres 


\section{perifèria}

Número 11, desembre 2009

www.periferia. name

universitats catalanes...

\section{I}

Dit això, em permetran que digui unes paraules per explicar de quina manera l'etnografia, l'etnologia i l'antropologia coexisteixen... I ho faré a partir de les meves vivències personals intentant mostrar de com aquests tres maneres de parlar de la nostra disciplina a més de coexistir s'interfereixen mútuament de tal manera que segons al meu entendre, avui que sembla estar més de moda el terme "antropologia", podríem dir que l'etnografia i l'etnologia tindrien que ser considerades com dues eines de l'antropologia però a condició que l'antropologia incorpori tant l'estudi de la nostra societat com el de les altres i que no es reservi exclusivament per a ella els aspectes teòrics de la nostra disciplina com ho semblava suggerir la tendència francesa i potser l'espanyola...

De totes maneres sense voler entrar en una controvèrsia que alguns podrien considerar estèril sobre el significat i valor d'unes simples etiquetes, intentaré dir, en primer Iloc, quatre mots que a mi em semblen importants sobre aquesta eina de la nostra disciplina que podem dir-ne etnografia en la seva versant del treball de camp en una altra societat. Després intentaré mostrar com l'etnografia (qualsevol forma d'etnografia) no es pot separar de l'etnologia si volem esdevenir antropòlegs...

Com em sembla que ja ho he dit o ho escrit, és útil recordar, en primer lloc, que qualsevol informació etnogràfica ha de considerar-se com una mena de confidència.

I que aquesta confidència només pot néixer d'una relació humana respectuosa, sincera, autèntica. I quan parlo de confidència o de simple relació, no ho faig des d'una perspectiva estrictament personal, aquella que pot donar-se entre l'antropòleg i un informador.

Per a mi, el camp relacional té de ser molt més ampli, ha d'abraçar la comunitat sencera no a través de tots i cadascun dels seus membres, la qual cosa seria impossible - sinó creant un clima de confiança que només pot instaurar-se quan l'etnògraf, abans d'exercir la seva tasca com a tal, assoleix que se li assigni un lloc 


\section{perifèria}

Número 11, desembre 2009

\section{www.periferia.name}

determinat en el si de la comunitat i no precisament com a etnògraf, que també, sinó sobretot com a veí o la d'un foraster respectuós amb les formes de viure i de pensar dels membres de la comunitat en la qual s'instal·la per a realitzar el seu treball de camp.

I aquesta manera de fer, al meu entendre, no ha de plantejar-se com una estratègia per millor assolir els seus propis objectius sinó com una actitud amarada d'autenticitat que ha de néixer dels principis deontològics que han de presidir l'activitat de l'etnògraf i sense els quals més valdria que s'abstingués de practicar aquesta professió.

L'etnògraf no és un senyor que es dedica a fer enquestes que casi sense cap preàmbul es dirigeix a una persona per obtenir amb un "si" o amb un "no", una resposta per omplir la seva casella i passar immediatament a un altre enquestat, oblidar el primer i així successivament col-laborar a que aquelles persones enquestades es transformin en números i percentatges.

Contràriament al tipus d'eficàcia exigida a aquest tipus d'enquestadors que es mesura segons el número de persones enquestades per hora o per dia, l'etnògraf ha d'entendre molt bé que en la seva feina quotidiana el saber perdre el temps és quelcom fonamental. I és això el que durant aquests anys de Grau hauran d'aprendre i els asseguro que aprendre "a saber perdre el temps" durant la seva vida d'etnògraf... els donarà molta feina.

La immersió en una societat diferent de la nostra no pot fer-se d'una altra manera. I per a mi, perdre el temps, és utilitzar-lo per a crear relacions humanes, per a descobrir l'entorn de la societat en la qual volem esdevenir antropòlegs, els seus carrers, el seus camins, les seves muntanyes i rius, la seva gent, les seves cases, els seus llocs de trobada, de treball, d'esbarjo i de vida social... sense cap bloc de notes entre les mans, ni llapis, ni camera, ni magnetòfon encara que sigui digital i imperceptible; sense cap protocol, pla o qüestionari encara que sigui molt ben elaborat; estant, anant, deixant-se amarar (empapar) de tot allò que envolta a l'etnògraf, aprenent la llengua que sempre és una inversió a llarg termini... Se perfectament que aquesta forma de perdre el temps es difícil de justificar als 


\section{perifèria}

Número 11, desembre 2009

\section{www. periferia. name}

organismes científics que han de subvencionar els nostres treballs de camp. Però jo penso que és el primer pas que cal donar. Donarem les explicacions burocràtiques que calguin, però no oblidarem que per l'etnògraf el temps no és or i que per aquesta raó pot permetre's el luxe de perdre'l. Els etnògrafs som els darrers quixots de les ciències socials. Però malgrat això també es cert que podrem justificar-lo (el temps perdut) i justificar-nos (com a quixots).

Aquest temps perdut o d'immersió és la fase prèvia del nostre treball. Ja vindran després els moments per fer la nostra etnografia en el sentit propi del terme tot recordant però que sempre les millors dades que obtindrem seran aquelles que sabrem caçar al vol, és a dir: sense voler-ho però estant sempre amatents a tot el que passa al voltant nostre.

Es per això que aquell llibre que vaig escriure i que es diu Soc fill dels evuzok li volia donar el títol De clariana en clariana que per a mi traduïa més bé la manera com jo entenia l'etnografia en aquell tros d'Àfrica on vaig esdevenir antropòleg: com una manera d'estar i conviure amb la gent tot aprenent les seves maneres de dir, de fer i de pensar... a poc a poc, sense preses... perquè resultaria que si en tinguéssim massa, de presses, perquè la subvenció rebuda per anar a estudiar, per exemple, els ritus funeraris entre els masai, era només d'un parell de mesos, podria passar - és un exemple - que en veure acabar-se el temps i constatar que no s'ha produït cap mort, l'etnògraf comenci a desitjar inconscientment la mort d'algú per a justificar la seva estada sobre el terreny...

Aquesta immersió - que sempre serà molt deficient (perquè mai parlarem sense accent la seva llengua; perquè essent adults ens comportarem com uns infants preguntant les coses més elementals; perquè sempre serem estrangers; perquè sempre guardarem - i així ha de ser - la nostra pròpia identitat...) aquesta immersió doncs no treu que de mica en mica anem fent la nostra etnografia que, com voldria dir-los, no es farà sola sinó que sempre anirà acompanyada de l'etnologia i potser de l'antropologia, perquè ens és impossible de dir-nos “ara sóc i faig d'etnògraf", "ara sóc i faig d'etnòleg", “ara sóc i faig d'antropòleg".... I és d'això el que ara voldria parlar. 


\section{perifèria}

Número 11, desembre 2009

\section{www.periferia.name}

Recordo que en els primers moments d'orientar els meus treballs de recerca sobre el terreny, volia comprendre almenys una mica tot allò que més o menys nosaltres entenem per "religió", "màgia" i "bruixeria".

Però ben aviat vaig plantejar-me un problema que no se ben bé si era un problema metodològic o teòric, etnològic, etnogràfic o antropològic, o tot plegat a la vegada. Fos el que fos em deia que cap d'aquells termes de religió, de màgia i de bruixeria em semblava pertinent per definir el camp de les meves recerques sobre el terreny.

I a més a més, per altra banda, em confrontava amb un problema que provenia de l'entorn més o menys intel-lectual d'origen europeu amb el que tenia relació, segons el qual sempre formulava un judici de valor negatiu envers aquells conceptes de màgia i de bruixeria.

No cal dir que per les esglésies cristianes, la desqualificació de la màgia i de la bruixeria era total.

Aquesta avaluació negativa de certes maneres de fer i de pensar d'aquella població, em posava nerviós, molt nerviós. I tampoc sé si aquella situació anímica meva entrava dintre dels cànons de l'etnografia, de l'etnologia o de l'antropologia (social o cultural)... el fet es que em va ajudar molt a trobar el bon camí, antropològicament parlant, per seguir les meves recerques etnogràfiques...

Recordo que un dia parlant amb un amic austríac professor d'economia de l'Institut panafricà pel Desenvolupament de la ciutat de Duala i que s'interessava molt pels aspectes culturals d'aquelles societats, li vaig dir: "Tinc ganes d'escriure quelcom sobre la religió, la màgia i la bruixeria evuzok" sense pronunciar ni una sola vegada aquests termes".

De fet, no ho he fet mai. La meva tesi de doctorat que tractava d'aquest tema és deia oficialment "Magie et sorcellerie".

Només vaig atrevir-me a dir que aquells conceptes no em semblaven pertinents. Uns anys després, en la seva publicació, feia desaparèixer aquell títol per substituirlo en un altre que era una dita evuzok "Ni dos ni ventre" (ni esquena ni ventre). En 


\section{perifèria}

Número 11, desembre 2009

\section{www.periferia.name}

aquest llibre a més a més de continuar dient que aquells termes de religió, màgia i bruixeria no em semblaven pertinents per investigar les realitats d'aquell tros d'Àfrica, proposava una certa equiparació d'aquests conceptes clàssics a les realitats africanes. Després vaig oblidar aquell tema. Tenia altres coses a fer. Només en parlo una mica en la cloenda del meu darrer Ilibre El sistema mèdic d'una societat africana, proposant una revisió d'aquests termes almenys pel que fa aquests pobles de l'Àfrica occidental...

En aquella conversa que mantenia amb el meu amic economista s'hi amagava certament un problema metodològic i potser un problema d'ordre teòric: què entenem per religió i màgia, sobretot quan estudiem les realitats africanes? Les paraules que deia al meu amic austríac em serviren si mes no per a dir-me que calia examinar aquells conceptes a partir de les pròpies categories dels evuzok i no de les nostres.

Podria dir que en aquells moments, sense saber-ho formalitzar en termes acadèmics, sense saber-ne ni tan sols la paraula, però deixant-me portar pel sentit comú, estava prenent una postura que em sembla que ara en diríem "èmica" per oposició a "ètica" - una distinció que vostès estudiaran a classe i sobre la qual la Professora Aurora González acaba de publicar-ne un llibre fent-nos veure que aquesta oposició no es res més que la història d'un malentès.

Sigui el que sigui, la posició èmica que jo considero com la recerca de les maneres com les coses son dites i pensades pels propis interessats, em semblava ser l'únic camí per endinsar-me en els paranys d'aquelles realitats tan complexes. Una vegada més doncs la recerca etnogràfica quedava influenciada per una postura metodològica o teòrica. L'etnògraf era al mateix temps etnòleg i/o antropòleg... Aquesta és almenys la meva opinió.

Aquesta actitud em va portar a entreveure que potser la noció d'evu, una categoria local, estava en el centre de moltes de les especulacions i pràctiques d'aquell poble. Els meus col-legues saben que aquesta noció ha estat al centre de les meves recerques que encara no considero acabades del tot. Per fer-me entendre ara, aquí, només diré que l'evu és considerat com un principi intern a la persona - diem com 


\section{perifèria}

Número 11, desembre 2009

www.periferia.name

l'ànima - que pot concedir al seu posseïdor un nou coneixement de la realitat i uns nous poders per actuar sobre ella, positivament o negativament.

Al cap de sis anys d'estar amb els evuzok, vaig anar-me'n a Paris. D'etnògraf o etnòleg autodidacta o més o menys carismàtic volia entrar al món acadèmic almenys com alumne... Tenia 36 anys. Per esdevenir antropòleg sempre s'hi és a temps...

En aquell temps, la meva preocupació central era l'examen d'aquesta noció. Una noció del mateix ordre que aquelles de mana, mangu, pfuna, orenda, baraka, duende... que es troben en moltes societats, tan africanes com d'altres. Tenia forces dades recollides durant els meus anys d'estada entre els evuzok. Unes que em permetien definir per se aquesta noció; d'altres que em permetien fer-ho in actu és a dir prenent en consideració la manera com els posseïdors d'aquell principi podien entrar en acció en determinats contextos com seria el cas dels grans medecinaires i dels mal anomenats bruixots, posseïdors d'evu social i antisocial respectivament. Vaig anar repassant moltes vegades les meves notes i les meves transcripcions; vaig escoltar de nou moltes de les meves cintes magnetofòniques que era com retrobar-me amb les veus d'aquelles persones amb qui havia fet el meu treball etnogràfic; vaig fer i desfer moltes vegades el meu pla; vaig mesurar amb molta cura allò que podria dir darrera de cada capítol o subcapítol; vaig fer molts esquemes cercant, fent i desfent les hipotètiques relacions que podien existir entre els elements que tenia davant meu; cercant les dades etnogràfiques que podien fer-les plausibles... Vaig intentar aplicar aquella tècnica de treball per una anàlisi estructuralista que Lévi-Strauss descriu molt bé en Anthropologie structurale (pp. 233). Durant el meu treball etnogràfic sobre el terreny vaig recollir varies variants del mite sobre l'origen de l'evu en el món dels homes. D'altres variants les vaig descobrir en biblioteques i arxius de Paris.

Fou així com la meva taula d'escriure que no era sinó una taula de cuina de fòrmica de color blau - era un simple estudiant amb una beca molt justeta - s'omplí de fitxes i per aproximacions successives, equivocacions i noves temptatives vaig anar trobant les analogies, les substitucions, les oposicions i diferents transformacions entre tots aquells elements que es relacionaven entre si a l'interior d'un sol i mateix 


\section{perifèria}

Número 11, desembre 2009

www.periferia.name

relat, i amb les altres versions d'aquest mite. La lectura diacrònica es va combinar amb una lectura sincrònica. Amb les fitxes distribuïdes sobre la taula com si jugués al solitari, fàcilment podia fer aquestes dues lectures. Pel que feia la lectura sincrònica, contemplant una fitxa sota una altra assenyalant un mateix esdeveniment o una mateixa relació de cada relat, fàcilment podia veure'n les homologies, les oposicions, les transformacions que s'hi podien operar. Era així com aquelles dues lectures em feien veure lentament la neta oposició entre el món de les clarianes i els seus habitants vivint en societat / i el món de la selva on tenia la seva seu l'evu, vivint tot sol en el tronc d'un arbre, menjant carn crua, sense conèixer el gran bé cultural que és el foc. I influenciat sense cap dubte per l'anàlisi levistrosià de la mitologia amerindia, em semblava poder reduir aquella oposició a aquella altra entre natura i cultura. Les homologies entre el món de l'evu / i el món d'aquells altres habitants de la selva en la seva realitat quotidiana o històrica, els pigmeus; el plec d'oposicions entre el món de les clarianes / i el món de la selva; l'examen de tot el bestiari relacionat amb l'evu, etc. em feia descobrir de mica en mica la riquesa d'aquells mites i altres relats.

El treball etnogràfic sobre el terreny era continuat per un treball d'anàlisi i d'interpretació, d'allò que em podem dir un treball de caire etnològic que, al mateix temps, m'obligava a fer de nou un treball etnogràfic, anant a les biblioteques, consultant els arxius del Museu de l'Home i de I'ORSTOM que no era res mes que el perllongament d'aquell treball etnogràfic et sobre el terreny... La qual cosa vol dir que mai les fases pròpies d'aquesta nostra disciplina estan deslligades les unes de les altres. Però continuem. El mite sobre l'origen de l'evu, en efecte, em va portar al mite sobre l'origen de les primeres llavors i a altres contes i dites [al camp de la literatura oral]; també em portà a establir certes relacions entre aquests mites i els ritus relacionats amb el món de l'evu [al camp del ritual].

De l'examen mitològic d'aquesta noció vaig passar a la seva classificació i de la seva classificació [al problema doncs de les classificacions] a la seva adquisició i transmissió ritual. 


\section{perifèria}

Número 11, desembre 2009

www.periferia.name

La natura indiferenciada de l'evu quedava clara ja des d'aquell moment de la tesi. Em semblava tenir els arguments etnogràfics necessaris per a demostrar-ho. L'expressió local "ni esquena ni ventre" n'era un exemple com nosaltres diem d'una cosa "que no te ni cap ni peus."

Mantindré aquesta posició fins avui i això malgrat les controvèrsies que he mantingut amb altres especialistes en aquesta matèria, (Philippe Labourthe-Tolra, Vivianne Baake, Alfred Afler...) i que defensen la teoria contrària segons la qual l'evu seria un principi pensat com intrínsecament o ontològicament - diuen antisocial o negatiu.

En un moment de la gran crisi econòmica com aquesta que estem vivint, parlar d'aquestes coses pot semblar-los una gran pèrdua de temps, com si estiguéssim discutint sobre el sexe dels àngels. Però no és així. El tema és important i té les seves conseqüències. L'evu és considerat com un element constitutiu de la persona humana. Considerar-lo al mateix temps com intrínsecament negatiu equival a dir que aquests pobles de l'Àfrica central es pensen a si mateixos com intrínsecament antisocials, malvats... com aquells autors que defensaven la natura corrupta dels salvatges...

Passen molts anys. Potser 35. Estic ja jubilat. De l'etnologia torno a l'etnografia, i sense proposar-m'ho, acompleixo al meu darrer acte com etnògraf. Mai és massa tard per fer una mica d'etnografia.

Fa tres anys, en efecte, vaig anar al Camerun, al país evuzok. No es tractava d'un nou viatge per continuar el meu treball de camp. Era un viatge d'ordre personal... Em volia acomiadar dels evuzok. El viatge tenia doncs un altre sentit. De totes maneres, malgrat això, no podia desfer-me completament de la meva persona d'etnògraf i guardava dintre meu, entre altres, aquella vella qüestió sobre el caràcter "intrinsecament negatiu" de l'evu que havia alimentat la controvèrsia entre els especialistes d'aquestes matèries. En vaig parlar una mica amb Éric de Rosny, a Yaundé, un col-lega amic meu. Coneixia perfectament la controvèrsia. Ell insistia molt en la dimensió històrica del contingut d'aquella noció. Tenia molta raó. Prenent en compte aquesta perspectiva, jo posava el meu accent en el procés de 


\section{perifèria}

Número 11, desembre 2009

\section{www.periferia.name}

satanització de l'evu à càrrec sobretot de les esglésies missioneres que hom pot ja descobrir en l'obra de l'alemany Günter Tessmann i això malgrat que aquest autor "no volia prendre en consideració el discurs dels missioners..." Per les esglésies doncs l'evu esdevingué "Satanàs" o bé un mbe nsisim, "un mal esperit": I'home que posseïa l'evu esdevenia així un home posseït pel dimoni, o per un "mal esperit", un ser antisocial per excel-lència, sense cap matís. En tenia molts testimoniatges. Però tornem al meu darrer viatge i a la meva posició sobre la natura (originalment) indiferenciada de l'evu, indiferenciada en el moment del naixement de l'infant; indiferenciada també al terme de certs rituals destinats sobretot als adults. A la vetlla del viatge de retorn cap a Barcelona, vaig passar gairebé tot el dia i tota la nit en un petit veïnat evuzok. Era un veïnat format pels fills i néts d'una família que jo havia conegut molt bé. Teníem petites converses amb els uns i amb els altres, bevíem vi de palmera, picàvem cacauets torrats... Al vespre, em trobava amb un grup de persones més aviat joves assegudes al "saló", al voltant d'una tauleta de centre de la casa. Parlàvem de moltes coses i de res en particular. Un dels presents però es va posar a fer-me preguntes sobre les meves recerques. Encetarem el tema de l'evu. En un moment d'aquesta conversa, vaig fer-li una pregunta com si es tractés d'una endevinalla. "Podries dir-me una cosa" "sense esquena ni ventre"?. Va reflexionar una mica i em respongué: "Un ou". Per a mi va ser una resposta que confirmava - a través d'un sol testimoni, és cert - aquella meva interpretació sobre el caràcter indiferenciat de l'evu representat sovint com una bola com ho deia en un llibre meu que s'intitulava Ni dos ni ventre, ni esquena ni ventre, una dita que suggeria una cosa informe, sense cap ni peus, com diríem nosaltres, com un ou, com va dir-me aquell jove evuzok. Va ser el meu darrer acte d'etnografia. Aquella resposta clara i contundent em causà una gran alegria interna. Em semblava confirmar una interpretació etnològica feta 35 anys abans.

L'anàlisi d'aquella noció m'havia portat en el moment de les meves recerques etnogràfiques sobre el terreny a orientar les meves investigacions vers el camp que per abreujar anomenaré de la "medecina autòctona". No per decisió personal prèvia sinó perquè les primeres recerques etnogràfiques i anàlisis sobre aquella noció d'evu o dit amb els nostres termes tradicionals, sobre la religió, la màgia i la 


\section{perifèria}

Número 11, desembre 2009

www.periferia.name

bruixeria, m’hi portaven casi sense voler-ho.

Això vol dir, al meu entendre, que l'etnografia ha de tenir una projecció totalitzant. Ja sé que les aproximacions holístiques no estan de moda i que fins i tot es creuen utòpiques, però jo penso que la visió totalitzant dels fets socials s'ha de mantenir almenys com a perspectiva o ideal. De vegades es preferible no assolir aquell ideal holistic i quedar-nos en una visió holística mancada, que assolir un perfecte estudi particular però que sempre apareixerà com un objecte d'estudi mutilat per una decisió metodològica.

I com ho acabo d'assenyalar, sovint son els mateixos fets que t'obliguen a prendre aquesta posició metodològica. Aquesta opció complica molt el treball de l'etnògraf. Els camps d'observació s'amplien i et porten per paranys inesperats. El temps no pot convertir-se en excusa per a portar a terme una investigació d'aquesta natura. Els poders acadèmics i econòmics ho haurien de comprendre. Concebre un projecte de recerca per un temps determinat (generalment molt curt) per passar després a un altre de nou és quelcom que restringeix notablement les possibilitats d'un coneixement especialitzat. L'aprenentatge d'una Ilengua demana temps. Integrar un tema d'estudi en els seu propi context, també. Immergir-se en una societat que no és la nostra encara més. El concepte de rendibilitat immediata no es pot aplicar a la nostra disciplina. I menys en termes econòmics. No pot ser que tots els antropòlegs esdevinguin generalistes. No comenceu els estudis de grau i seguir els de màster i potser els de doctorat per acabar fent "informes" per encàrrec d'un ajuntament... Hem de defensar la idea de que en la nostra disciplina són necessaris els especialistes i que el treball de camp no serveixi únicament per a preparar una tesi sinó que sigui quelcom que ens acompanyi tota la vida. Els estudis de tres mesos sobre el terreny, en el nostre camp, haurien de desaparèixer...

Va ser doncs aquest esperit totalitzant o holistic, si es vol, el que em va anar portant de la noció d'evu, a la medecina, al ritual, a l'etnobotànica, a la literatura oral i a molts altres aspecte de la vida d'aquella societat...i ara, finalment, durant la meva jubilació, m'ha portat a l'estudi d'alguns aspectes de l'art d'aquella regió. Si vaig començar amb aquella tesi de doctorat de tercer cicle que, en publicar-la, portava el nom de "Ni esquena ni ventre", ara, aquest estudi sobre art que el 


\section{perifèria}

Número 11, desembre 2009

www.periferia.name

considero una mica com un doctorat no de "tercer cicle" sinó de "la tercera edat", penso intitular-lo "Esquena o ventre" perquè em permet pensar, almenys etnogràficament, el pas de la indiferenciació, a la diferenciació de les coses d'aquest món. I aquest és un problema etnològic o antropòlogic...

Em perdonaran que hagi tingut tan poca modèstia parlant de mi mateix, d'alguns aspectes que em portaren a esdevenir etnògraf, etnòleg o antropòleg, encara no ho sé ben bé.

El que si em sembla saber és que

- Esdevenir antropòleg és conviure constantment amb aquestes tres moments de la nostra disciplina, ens diguin etnògrafs, etnòlegs o antropòlegs.

- Esdevenir antropòleg és sortir de si mateix, d'obrir-se als altres.

- És intentar comprendre les altres maneres de dir, de fer i de pensar el món, tot mantenint el convenciment que sempre quedarem molt lluny d'assolir aquest coneixement.

- Esdevenir antropòleg és aprendre a relativitzar la nostra manera de pensar les coses i acceptar que per a pensar-les, dir-les o fer-les es poden seguir moltes lògiques.

- Esdevenir antropòleg és estar convençut que aquestes lògiques no són fàcils de captar i per això preparar-se per esdevenir-ne és com caminar per uns paranys que no saps ben bé per on poden portar-te i que per bons que siguin els guies sempre hauràs de caminar-los en solitari. I a mesura que un va caminant i dominant el paisatge que t'envolta, el teu sentiment de solitud és encara més gran perquè de tan fixar-te en aquell racó de bosc o de camí, en aquell arbre o en aquella pedra, [la nostra especialitat] arribes a veure textures i tonalitats que els altres no veuen i voldries que veiessin; fins i tot pots oblidar-te dels altres arbres del bosc.

- Esdevenir antropòleg són moltes hores, mesos, anys de dedicació; són moltes hores de biblioteca, d'arxius, de treball sobre el terreny; són també moltes hores de lectura, de converses; són moltes planes escrites, 


\section{perifèria}

Número 11, desembre 2009

\section{www.periferia.name}

esborronades, estripades.

- Esdevenir antropòleg són molts camins que no porten a enlloc, abandonats; miratges que t'omplen d'il/lusions, i s'esfumen amb un dos i no res com si estiguéssim en ple desert.

- Esdevenir antropòleg pot ser un somni, però pot causar també molts insomnis.

- Esdevenir antropòleg comporta identificacions estranyes amb un autor, amb una idea, amb una escola de pensament, amb una teoria que la fas teva, poc a poc; idees que et semblen genials i que al cap d'uns dies veus que no ho son tant.

- Esdevenir antropòleg són dies i mesos que semblen perduts, decepcions; però també alegries, grans alegries per haver trobat el teu camí, per haver descobert alguna cosa sobre l'altre, sobre si mateix; potser el mot exacte en l'article o l'exercici que estàs fent, l'argument convincent, el terme just, la dada adient, el fil que ho lliga tot.

- Esdevenir antropòleg és obrir moltes portes, les portes d'un coneixement que pot prendre moltes direccions diferents.

- Esdevenir antropòleg és, per últim, viure moltes alegries, l'alegria de que tots som iguals però diferents; una alegria que moltes vegades serà incompresa per l'entorn, esdevindrà silenciosa però pregona, molt pregona sobretot quan veus que aquell manyoc d'idees mal girbades en un començament, aquell plec d'hores que semblaven perdudes, aquells ensenyaments que consideraves llargs i pesats, aquells treballs personals sobre el terreny o en un estudi ple de llibre, de llibretes i apunts... van prenent forma i color, un color que permet fer comprendre als altres que les diferents maneres de pensar el món no han de desaparèixer per una determinada uniformitat que alguns ens volen imposar i menys encara per un afany desmesurat de rendibilitat econòmica de la nostra disciplina. 